\title{
Hypotension after spinal anaesthesia is not always the rule in parturients undergoing caesarean section
}

\author{
Mona Refaat Hosny ${ }^{I^{*}}$, Mohamed Saleh Ahmed ${ }^{2}$, Wail Ahmed Abdelaal, Dalia M Elfawy ${ }^{1}$ \\ Assistant Professor of Anaesthesiology ${ }^{1}$, Lecturer ${ }^{2}$, Faculty of Medicine, Ain-Shams University, \\ Cairo, Egypt \\ *Corresponding author: monamourmar@hotmail.com \\ ORCID ID: $\underline{\text { https://orcid.org/7027120 }=8066}$ \\ DOI: http:/doi.org/10.4038/slia.v28i2.8598
}

\begin{abstract}
Background
General anaesthesia is a real challenge for the anaesthetist when anaesthetizing obstetric patients due its well-known complications of difficult intubation and thereby increasing morbidity and mortality of pregnant women. These risks can be easily avoided by regional anaesthesia.

Spinal anaesthesia is frequently associated with hypotension which can have detrimental effects both on the mother and the neonate. Prophylactic phenylephrine administration had been widely practiced to prevent post-spinal hypotension during caesarean section. The goal of this study is to prove and determine that it is not always necessary to use a vasoconstrictor to avoid hypotension after spinal anesthesia for parturients undergoing caesarean section.
\end{abstract}

\section{Methods}

We enrolled 100 patients in this randomized controlled study who were having elective caesarean delivery.

Spinal anaesthesia was performed under aseptic conditions. Immediately following spinal blockade, patients were randomly allocated to receive either a single bolus of phenylephrine $100 \mu \mathrm{g}$ in a volume of $10 \mathrm{ml}$, or equivalent volume of normal saline $0.9 \%$.

Incidence of post-spinal hypotension was used as the primary outcome. Maternal haemodynamic parameters, intraoperative nausea and vomiting, the need for phenylephrine or glycopyrrolate administration, neonatal Apgar score at 1, 5 minutes, and base excess (BE) value of the neonatal umbilical venous blood were all recorded and reflected the secondary outcome

\footnotetext{
Results

There was no significant difference regarding the incidence of post-spinal hypotension in phenylephrine and placebo group. There was no difference in neonatal Apgar score at 1, 5 minutes, and base excess in both groups.
}

\section{Conclusion}

The present study had demonstrated that it is not always necessary to provide a vasoconstrictor to avoid hypotension that results from spinal anaesthesia in caesarean sections.

Keywords: Caesarean delivery; vasoconstrictors; regional blockade

\section{Introduction}

It is well known that performing spinal anaesthesia for caesarean delivery decreases the risk of morbidity and mortality of general anaesthesia which could expose the obstetric patient to incidence of difficult intubation or Mendelson's syndrome.

It is as well-known that hypotension is a very common complication after spinal anaesthesia particularly in obstetric patients undergoing caesarean delivery and it's probable and possible sequalae on both the mother and the foetus in deceasing the utero-placental blood flow resulting in fetal acidosis. ${ }^{1}$

Over the last two decades, studies compared ephedrine versus alpha adrenergic agonists in avoiding foetal acidosis after caesarean sections.

Phenylephrine is a synthetic noncatecholamine $\alpha_{1}$ adrenergic agonist that has 
a short duration of action being metabolized by catechol O-methyltransferase and monoamine oxidase. Phenylephrine was considered not suitable for obstetric anaesthesia because of the concerns regarding vasoconstriction induced diminished placental blood flow. ${ }^{2}$

The goal of this study is to prove and demonstrate that it is not always necessary to use a vasoconstrictor to avoid hypotension after spinal anaesthesia for parturients subject to caesarean delivery.

\section{Patients and Method}

This study was performed at Ain Shams University Maternity Hospital after obtaining consent from all patients and getting the ethical committee approval. The study was registered on Pan African Clinical Trials Registry.

100 patients were enrolled into this prospective double blinded randomized controlled study. Inclusion criteria were ASA I or II patients, full term, single pregnancy, elective caesarean section, aged 20-35 years old, and height 160-170 $\mathrm{cm}$. Exclusion criteria were emergency caesarean section, any maternal or fetal comorbidity, or a BMI $>35 \mathrm{~kg} / \mathrm{m}^{2}$.

Patients were randomly divided into two equal groups using computer-generated sequence. Allocation concealment was done using sequentially numbered, opaque sealed envelopes. The envelope was opened, and subsequent injectant was prepared by clinical pharmacist. Data collection and data analysis were done by anaesthetist who was blinded to the patient's allocation group.

Anaesthetic technique was standardized for all patients. After careful history taking, a thorough physical examination was conducted which included assessment of the mother's general condition, cardiac, chest and airway examination and a review of the results of laboratory investigations.

Patients were premedicated with ranitidine $150 \mathrm{mg}$ given two hours before arriving to the operative theatre. Metoclopramide $10 \mathrm{mg}$ and $\mathrm{Na}$ citrate syrup $30 \mathrm{ml}$ were also given 30 minutes before arriving to the operative theatre. Midazolam 2mg was given upon admission to the operative theatre.

In both groups and just before being admitted to theatre, patients were preloaded with $500 \mathrm{ml}$ of ringer lactate solution and another $500 \mathrm{ml}$ was given whilst performing the spinal anaesthetic.
In the operating theatre, all patients were put on ASA standard monitoring, including 5 lead ECG, non-invasive blood pressure monitoring and pulse oximetry for oxygen saturation. Baseline values were recorded for all patients. Any deviation from normal values subjected the parturient involved to be excluded from the study.

Spinal anaesthesia was performed in the left lateral decubitus position under aseptic conditions, using 25-gaugeWhitacre needle at lumbar level 3-4. Hyperbaric levobupivacaine $0.5 \%(7.5 \mathrm{mg})$, and fentanyl $25 \mu \mathrm{g}$, were slowly injected over a period of 30 seconds after observing CSF flow.

Immediately following spinal blockade, patients were turned into supine position with $15^{0} \mathrm{left}$ lateral tilt to avoid aortocaval compression. Face oxygen mask 5 liters was applied. Patients were randomly allocated into one of the following groups:

- Group 1: received a single bolus of phenylephrine $100 \mu \mathrm{g}$ in $10 \mathrm{ml}$ normal saline (phenylephrine hydrochloride solution, Claris Lifesciences, Inc., India).

- Group 2: received equivalent volume of normal saline $0.9 \%$

The injectant was anonymous to the anaesthetist who was performing the spinal anaesthesia. After performing the block, the patient was immediately turned to the supine position with 15 degrees left lateral tilting. Sensory blockade was assessed bilaterally using cold ice. T5 block was considered satisfactory. and this level was achieved to all of our patients included in this study.

Surgeon was allowed to start surgery 5 minutes after the spinal anaesthesia. Any deviation from the above criteria rendered the patient to be excluded from the study.

Blood pressure was measured every 2 minutes till skin incision and every 5 minutes thereafter. Hypotension was considered if systolic pressure decreased below 30\% from the patient baseline value or if she experienced any kind of dizziness, nausea, vomiting or respiratory depression. A bolus dose of open label phenylephrine $0.1 \mu \mathrm{g} /$ $\mathrm{kg}$ was injected on this occasion as a rescue and was recorded.

Any drop of the heart rate below 50 beats / minute, glycopyrrolate $0.1 \mathrm{mg}$ was given. 
Another $500 \mathrm{ml}$ of ringer lactate solution was started slowly after delivery of the baby to which $20 \mathrm{IU}$ of oxytocin was added and was continued till the patient was discharged to the recovery room.

\section{Parameters of the study}

Incidence of post-spinal hypotension was used as the primary outcome. Post-spinal hypotension was defined as a decrease in the systolic arterial pressure below $30 \%$ from the baseline value, or the patient became symptomatic in the form of dizziness, nausea, vomiting or respiratory depression. ${ }^{3}$

Maternal haemodynamic parameters, intraoperative nausea and vomiting, the need for phenylephrine or glycopyrrolate, neonatal Apgar score at 1, 5 minutes, and base excess (BE) value of the neonatal umbilical venous blood were measures of the secondary outcome.

\section{Statistical analysis}

Data were analyzed using Statistical Package for Social Science (SPSS) version 21.0. Chicago, Illinois, USA. Quantitative data were expressed as mean \pm standard deviation. Qualitative data were expressed as count and percentage. The independent-samples t-test was used to compare between means in the two groups, and independent samples-median test was used to compare between medians in both groups. Chi square test was used to compare proportions between two qualitative parameters. $\mathrm{P}<0.05$ was considered significant and $\mathrm{P}<0.01$ was considered highly significant.

\section{Sample size calculation}

Sample size was calculated using PASS program, setting alpha error at $5 \%$, and power at $80 \%$, assuming $20 \%$ difference between the 2 study groups, produced a minimal sample size of 42 per group, rounded to 50 cases per each group.

\section{Results}

The study enrolled pregnant ladies between 20 and 35 years of age and their gestational age was between 39 and 40 weeks.

Equal amount of fluids was administered to both groups until the baby's delivery. Nausea and vomiting were higher in the control group, but without clinical significance (6 in phenylephrine group while 8 in control group). There was difference regarding rescue dose administration and of extra phenylephrine and glycopyrrolate given in both groups (Table 1). Findings which were evaluated among pregnant women enrolled showed no significant difference regarding the incidence of hypotension (need for phenylephrine) (Table 1) between the two groups, however there was decrease in mean systolic blood pressure in both groups at T1, T2 as well as incidence of tachycardia, reactive hypertension and need for infusion discontinuation. There was no statistical difference between the two groups as reflected in (Figure 1,2). Clinical evaluation of newborns showed no difference in Apgar scores at the 1st minute; was 8 in both groups and then became 10 in 5th minute between the two groups, the acid base of umbilical blood sample (Base excess was 1.714 at phenylephrine group, 1.738 in control group without significant difference) (Table 2)

Table 1: Descriptive analysis of the parturients, side effects and rescue doses needed

\begin{tabular}{|l|l|l|l|}
\hline & $\begin{array}{l}\text { Group } \\
\text { phenylephrine } \\
\mathbf{( 5 0 )}\end{array}$ & $\begin{array}{l}\text { Control group } \\
\mathbf{( 5 0 )}\end{array}$ & P value \\
\hline Age (years) & $29.10 \pm 3.683$ & $28.58 \pm 2.612$ & $0.417^{\circ}$ \\
\hline $\begin{array}{l}\text { Gestational age } \\
\text { (weeks) }\end{array}$ & $39.876 \pm .3761$ & $39.810 \pm .3559$ & $0.370^{\circ}$ \\
\hline $\begin{array}{l}\text { Nausea \& vomiting } \\
\text { no. of patients (\%) }\end{array}$ & $6(12 \%)$ & $8(16 \%)$ & $0.564^{*}$ \\
\hline $\begin{array}{l}\text { Need for } \\
\text { phenylephrine no. of } \\
\text { patients (\%) }\end{array}$ & $4(8 \%)$ & $10(20 \%)$ & $0.084^{*}$ \\
\hline $\begin{array}{l}\text { Need for } \\
\text { glycopyrrolate no. of } \\
\text { patients (\%) }\end{array}$ & $3(6 \%)$ & $8(16 \%)$ & $0.110^{*}$ \\
\hline
\end{tabular}

Data are presented as mean \pm SD or count (\%)

Measured by independent t-test

*Measured by chi-square test

Table 2: Neonatal parameters in both groups

\begin{tabular}{|l|l|l|l|}
\hline & $\begin{array}{l}\text { Group } \\
\text { Phenylephrine } \\
(\mathbf{5 0 )}\end{array}$ & $\begin{array}{l}\text { Control } \\
\text { group } \\
\mathbf{( 5 0 )}\end{array}$ & P value \\
\hline $\begin{array}{l}\text { Apgar score 1 } \\
\text { minute }\end{array}$ & $8(7-9)$ & $8(7-9)$ & $0.758^{\circ}$ \\
\hline $\begin{array}{l}\text { Apgar score 5 } \\
\text { minutes }\end{array}$ & $10(9-10)$ & $10(9-10)$ & $0.538^{\circ}$ \\
\hline $\begin{array}{l}\text { Base excess BE } \\
\text { (meq/l) }\end{array}$ & $1.714 \pm 0.247$ & $1.738 \pm 0.219$ & $0.609^{*}$ \\
\hline
\end{tabular}

Data are presented as mean \pm SD or median(range) ${ }^{\circ}$ Measured by independent samples median test *Measured by independent t-test 


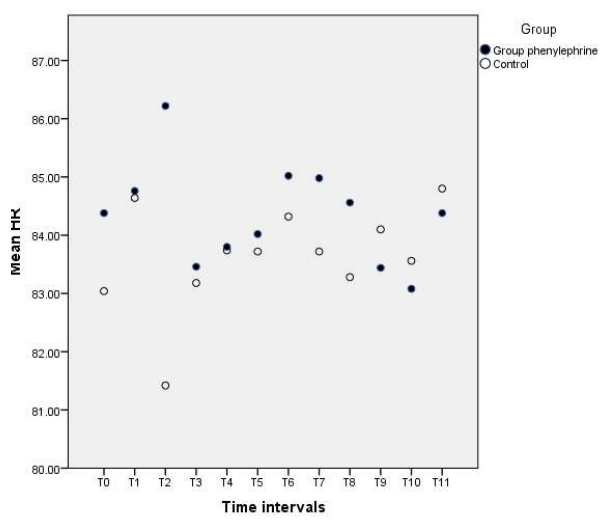

Figure 1: Scatter plot showing mean heart rate in both groups at different time intervals

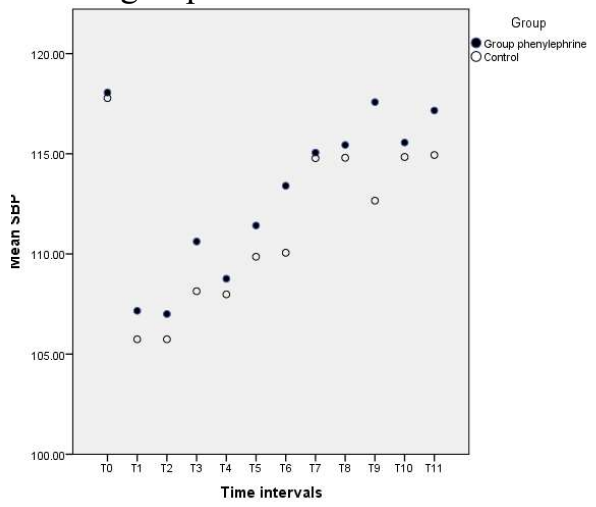

Figure 2: Scatter plot showing mean systolic blood pressure in both groups at different time intervals

\section{Discussion}

Spinal anaesthesia had become the recommended anaesthetic technique for elective caesarean section, as it is associated with a relatively lower risk when compared to general anaesthesia.

However, spinal anaesthesia is still associated with complications of post-spinal hypotension which is not uncommon as per most research work worldwide. Post spinal hypotension may lead to lower placental perfusion, which is associated with neonatal acidosis and may lead to potentially unfavorable neonatal outcome. Early detection of post-spinal hypotension and proper management could effectively prevent maternal and neonatal complications. ${ }^{1}$

Post-spinal hypotension could be prevented and managed by intravenous fluid infusion, avoidance of aortocaval compression, and reasonable use of vasopressors. Yet, there is no single intervention that had demonstrated the avoidance of the use of vasoconstrictors in the management of post-spinal hypotension. ${ }^{4}$

No significant difference was found in the two study groups with regards to post spinal hypotension in both placebo and phenylephrine group. This could be explained by the adequate fluid preloading, as all our patients were hydrated with $500 \mathrm{ml}$ of ringer's lactate, which was started before spinal anaesthesia. Although, Ueyama and colleagues have shown an inadequacy of fluid hydration due to rapid fluid redistribution ${ }^{5}, \mathrm{Xu}$ and colleagues calculated the effective volume of fluid preload to prevent post-spinal hypotension to be approximately $13 \mathrm{~mL} . \mathrm{kg}-1 .^{6}$

Fear of aortocaval compression is routine in obstetric anaesthesia and that is supported by history and tradition. Patient positioning in supine with a 15-degree left lateral tilt after spinal anaesthesia had shown to be associated with less post-spinal hypotension, and improved cardiac output. $^{7}$

Based on statistical analysis of computerized anaesthesia records, Brenck and colleagues identified maternal age, body mass index, and peak sensory block height as independent risk factors for post-spinal hypotension. ${ }^{8}$

In fact, advanced maternal age had been identified as a risk factor of post-spinal hypotension during caesarean section in a few number of studies which assessed multiple risk factors ${ }^{8-9}$ with one study suggesting maternal age greater than 35 being the cut-off value. ${ }^{12}$ Maternal age ranged between 20-35 years in our study. Moreover, incidence of hypotension is more common in patients with high body mass index (BMI) varying between 25 and $29 \mathrm{~kg} / \mathrm{m}^{2}$ which was the cutoff point. ${ }^{10}$ In the present study, patients' BMI was less than $30 . \mathrm{kg} / \mathrm{m}^{2}$.

There are multiple factors that can affect intrathecal drug spread and thus the peak of the sensory block height including physical characteristics of injected solution, clinical technique during spinal anaesthesia, and the patient characteristics. ${ }^{11}$ It had been demonstrated that intrathecal hyperbaric bupivacaine had a more rapid onset of sensory blockade when compared to isobaric bupivacaine. ${ }^{12}$ Moreover, low-dose intrathecal levobupivacaine limits postspinal hypotension. ${ }^{13}$ In the present study, we used a low dose of hyperbaric levobupivacaine 
supplemented with intrathecal fentanyl. which were injected at a very slow pace over 30 secs hence adopting optimal conditions to avoid hypotension. The local anaesthetic dose used was similar to that used by other authors in likewise studies. ${ }^{14,15}$

Selection of ideal vasopressor for management of post-spinal hypotension is a matter of debate. Systematic reviews and meta-analysis of clinical trials demonstrated that phenylephrine and ephedrine were both effective in preventing postspinal hypotension. However, phenylephrine was associated with a lower risk of fetal acidosis when compared to ephedrine..$^{2.16,17}$ In this study, prophylactic bolus of phenylephrine used was close to the effective dose $95 \mathrm{micgs}$ proposed by Tanaka and colleagues, as they demonstrated that lower doses of phenylephrine bolus (60-80 ug) may not be as effective as larger doses (90-120 ug) in preventing post-spinal maternal hypotension. ${ }^{18}$

Interestingly, a recent meta-analysis by Singh and colleagues demonstrated that prophylactic use of phenylephrine, and ephedrine had the highest probability among other vasopressors used to adversely affect fetal acid-base status, and thus fetal outcome. ${ }^{19}$ In another meta-analysis by Fitzgerald and colleagues showed that phenylephrine had caused maternal bradycardia more common than other vasopressors which were used. ${ }^{20}$

Our study demonstrated that, if the risk factors for post-spinal hypotension were avoided, prophylactic vasopressor administration might not be always necessary.

\section{Conclusions}

Based on the inclusion criteria, post-spinal hypotension was not significantly manifested in the patients enrolled in our study in both phenylephrine and placebo group, hence it is to be concluded that with careful considerations of certain precipitating factors which could predispose to hypotension, caesarean sections can be easily conducted without the need of vasopressors.

Further research work and metanalyses are still needed on a wider and broader scale of patients.

\section{References:}

1. Mavridou I, Stewart A, Fernando R. Maternal Hypotension During Spinal Anesthesia for Cesarean Delivery. Current Anesthesiology Reports. 2013;3(4):282-91. https://doi.org/10.1007/s40140-013-0036-3

2. Lee A, Ngan Kee WD, Gin T. A quantitative, systematic review of randomized controlled trials of ephedrine versus phenylephrine for the management of hypotension during spinal anesthesia for cesarean delivery. AnesthAnalg. 2002;94(4):920-6, https://doi.org/10.1097/00000539-200204000$\underline{00028}$ PMid:11916798

3. K1ÖHr S, Roth R, Hofmann T, Rossaint R, Heesen M. Definitions of hypotension after spinal anaesthesia for caesarean section: literature search and application to parturients. Acta AnaesthesiologicaScandinavica.

2010;54(8):909-21.

https://doi.org/10.1111/j.13996576.2010.02239.x PMid:20455872

4. Chooi C, Cox JJ, Lumb RS, Middleton P, Chemali M, Emmett RS, et al. Techniques for preventing hypotension during spinal anaesthesia for caesarean section. Cochrane Database Syst Rev. 2017;8:CD002251. https://doi.org/10.1002/14651858.CD002251.pu $\underline{\mathrm{b} 3}$ PMid:28976555 PMCid:PMC6483677

5. Ueyama H, He YL, Tanigami H, Mashimo $\mathrm{T}$, Yoshiya I. Effects of crystalloid and colloid preload on blood volume in the parturient undergoing spinal anesthesia for elective Cesarean section. Anesthesiology.

1999;91(6):1571-6.

https://doi.org/10.1097/00000542-199912000$\underline{00006}$

PMid:10598596

6. Xu S, Wu H, Zhao Q, Shen X, Guo X, Wang F. The Median Effective Volume of Crystalloid in Preventing Hypotension in Patients Undergoing Cesarean Delivery with Spinal Anesthesia. Brazilian Journal of Anesthesiology.

2012;62(3):312-24.

https://doi.org/10.1016/S0034-7094(12)70132-0

7. Lee AJ, Landau R. Aortocaval Compression Syndrome. Anesthesia \& Analgesia.

2017;125(6):1975-85.

https://doi.org/10.1213/ANE.0000000000002313 PMid:28759487

8. Brenck F, Hartmann B, Katzer C, Obaid R, Bruggmann D, Benson $\mathrm{M}$, et al. Hypotension after spinal anesthesia for cesarean section: identification of risk factors using an anesthesia information management system. J Clin MonitComput. 2009;23(2):85-92. https://doi.org/10.1007/s10877-009-9168-x PMid:19277879 
9. Kyokong O, Charuluxananan S, Sriprajittichai P, Poomseetong T, Naksin P. The incidence and risk factors of hypotension and bradycardia associated with spinal anesthesia. J Med Assoc Thai. 2006;89 Suppl 3:S58-64.

10. Jayachandran CG ML. Correlative Study between Body Mass Index and Hypotension in Obese Patients Undergoing Cesarean Section under Spinal Anaesthesia. International Journal of Scientific Study. 2017;5(4):5.

11. Hocking G, Wildsmith JAW. Intrathecal drug spread. British Journal of Anaesthesia.

2004;93(4):568-78.

https://doi.org/10.1093/bja/aeh204

PMid:15220175

12. Sia AT, Tan KH, Sng BL, Lim Y, Chan ESY, Siddiqui FJ. Use of hyperbaric versus isobaric bupivacaine for spinal anaesthesia for caesarean section. 2013.

https://doi.org/10.1002/14651858.CD005143.pub2

13. Arzola C, Wieczorek PM. Efficacy of low-dose bupivacaine in spinal anaesthesia for Caesarean delivery: systematic review and meta-analysis. $\mathrm{Br}$ J Anaesth. 2011;107(3):308-18. https://doi.org/10.1093/bja/aer200

14. Goyal A, Shankaranarayan P, Ganapathi P. A randomized clinical study comparing spinal anesthesia with isobaric levobupivacaine with fentanyl and hyperbaric bupivacaine with fentanyl in elective cesarean sections. Anesth Essays Res. 2015;9(1):57-62. https://doi.org/10.4103/0259-1162.150169 PMid:25886422 PMCid:PMC4383120

15. Thakore S, Thakore N, Chatterji R, Chatterjee C, Nanda S. Evaluating the efficacy of low-dose hyperbaric levobupivacaine versus hyperbaric bupivacaine along with fentanyl for subarachnoid block in patients undergoing medical termination of pregnancy and sterilization: A prospective, randomized study. Journal of Obstetric Anaesthesia and Critical Care. 2018;8(2):90-5. https://doi.org/10.4103/joacc.JOACC 5117

16. Veeser M, Hofmann T, Roth R, Klohr S, Rossaint $\mathrm{R}$, Heesen M. Vasopressors for the management of hypotension after spinal anesthesia for elective caesarean section. Systematic review and cumulative meta-analysis. Acta Anaesthesiol Scand.2012;56(7):810-6.

https://doi.org/10.1111/j.1399-

6576.2011.02646.x

PMid:22313496

17. Lin FQ, Qiu MT, Ding XX, Fu SK, Li Q. Ephedrine versus phenylephrine for the management of hypotension during spinal anesthesia for cesarean section: an updated metaanalysis. CNS NeurosciTher. 2012;18(7):591-7. https://doi.org/10.1111/j.1755-

5949.2012.00345.x

PMid:22759268 PMCid:PMC6493492
18. Tanaka M, Balki M, Parkes RK, Carvalho JC. ED95 of phenylephrine to prevent spinal-induced hypotension and/or nausea at elective cesarean delivery. Int J ObstetAnesth.

2009;18(2): 125-30.

https://doi.org/10.1016/j.ijoa.2008.09.008

PMid:19162468

19. Singh PM, Singh NP, Reschke M, Ngan Kee WD, Palanisamy A, Monks DT. Vasopressor drugs for the prevention and treatment of hypotension during neuraxial anaesthesia for Caesarean delivery: a Bayesian network meta-analysis of fetal and maternal outcomes. British Journal of Anaesthesia. 2020;124(3):e95-e107. https://doi.org/10.1016/j.bja.2019.09.045 PMid:31810562

20. Fitzgerald JP, Fedoruk KA, Jadin SM, Carvalho B, Halpern SH. Prevention of hypotension after spinal anaesthesia for caesarean section: a systematic review and network meta-analysis of randomised controlled trials. Anaesthesia. 2019;75(1):109-21.

https://doi.org/10.1111/anae.14841 PMid:31531852 